\title{
Rash Acneiform, CTCAE
}

National Cancer Institute

\section{Source}

National Cancer Institute. Rash Acneiform, CTCAE. NCI Thesaurus. Code C143798.

A disorder characterized by an eruption of papules and pustules, typically appearing in face, scalp, upper chest and back. 